\title{
EVALUATION OF CONSUMER BEHAVIOR IN THE BUILDING MECHATRONICS RESEARCH CENTRE
}

\author{
Éva ÁDÁMKÓ \\ Dep. of Electrical Engineering and Mechatronics \\ University of Debrecen \\ Debrecen, Hungary \\ adamko.eva@eng.unideb.hu
}

\begin{abstract}
At the University of Debrecen the department of Electrical Engineering and Mechatronics works in a so-called Building Mechatronics Research Centre, where the researchers took the first steps of construction of an intelligent and sustainable building so the research infrastructure is configured. Several publications deal with the research centre from the building engineering approach, in this article we would like to describe briefly the applied measurement methods, which are principally conduce to monitor the energy consumption of the building to support the energy efficiency realization.
\end{abstract}

Keywords- energy efficiency; energy consumption; intelligent building; measurement method

\section{INTRODUCTION}

In 2013 N. Tóth et.al. gave detailed introduction the building engineering solutions of the Building Mechatronics Research Centre in [1]. This article described the several green-energy producing and automation supporting devices in the research centre, like for example the heat-pump system with air channel, the vacuum-tube solar collector and some solar cells with rotating stand. In the time since the article appeared many developments have been made in the research center resulting that today we have a global solar exposure meter, an internal sensor network, a meteorological station and two building management systems, so the machine park is suitable for the implementation of an intelligent building.

\author{
Péter T. SZEMES \\ Dep. of Electrical Engineering and Mechatronics \\ University of Debrecen \\ Debrecen, Hungary \\ szemespeter@eng.unideb.hu
}

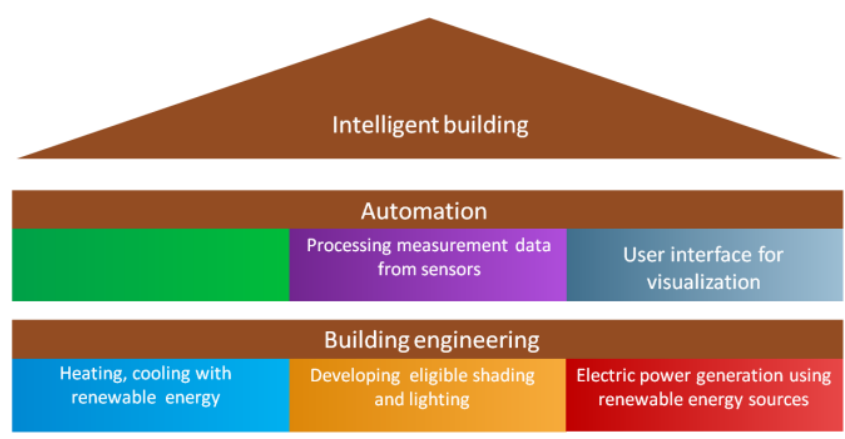

A construction with proper thermal characteristics

Fig. 1.: Intelligent building

\section{MEASUREMENT TECHNOLOGY REALIZATION}

As we know the eligible machine park is not enough to declare a building as it is intelligent. We need a final automation system which can control the building engineering part of the research centre, by using the received measurement quantities. Setting this precise aim, over the last few months we created a comprehensive, universal system which can monitor the machine park of the research center.

From the previous lists it is easy to see that in the research centre measurement devices in wide ranges provide different measured quantities. Processing and validating the large amount of these different quantities which come from different measurement devices requires huge time and energy efforts, so we need some support to get real usable information. To be more precise we need some IT support to evaluate these data, which was the reason we implemented a four-level measuring system in the Building Mechatronics Research Center. The levels are the next:
1) Measurement method
2) Measurement configuration
3) Data validation
4) Data visualization 


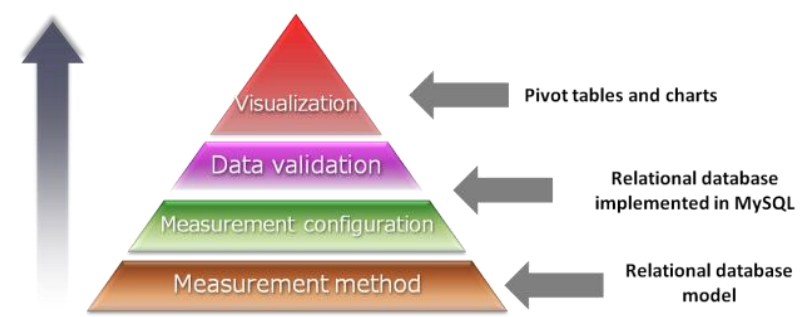

Fig. 2.:Measurement levels

The primary purpose of the above mentioned instruments is different, and mostly this goal is not measuring some physical property. But all can be considered as a general sensor object which has a measured physical quantity result. All of these results are different in their type, unit, digital representation and these devices communicate through different communication channels. The large amount and the differences make hard to process these data. For every device we need a unique processing program, and a unique engineer who is an expert of the instrument.

In order to solve the data processing problem of different data which come from various devices we designed a database scheme named Measured data collector. The scheme was realized as a relational database model, which contains in the base state four tables. It would be possible to use other database model techniques, but relational database advantages e.g., ease of use, flexibility, precision and general properties like use of keys, avoiding data redundancy, constraining the input, maintaining data integrity, rights, structured query language fit the most of our aims and the implementation was made in MySQL.

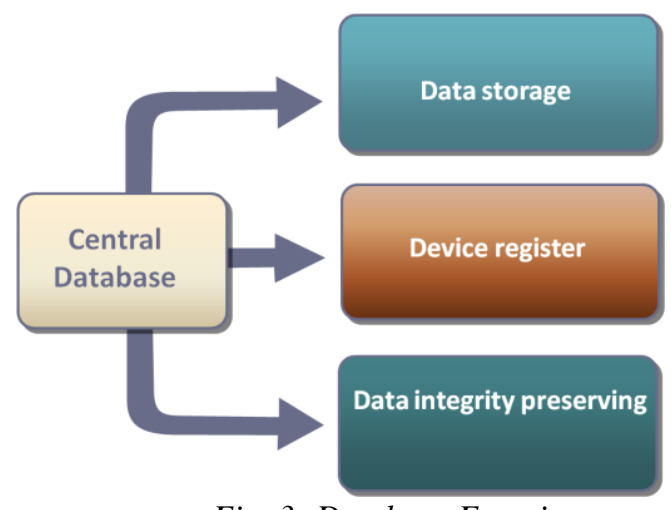

Fig. 3.:Database Functions

Measured data collector database realizes three functions:

1) data storage,

2) device register,

3) and data validation.

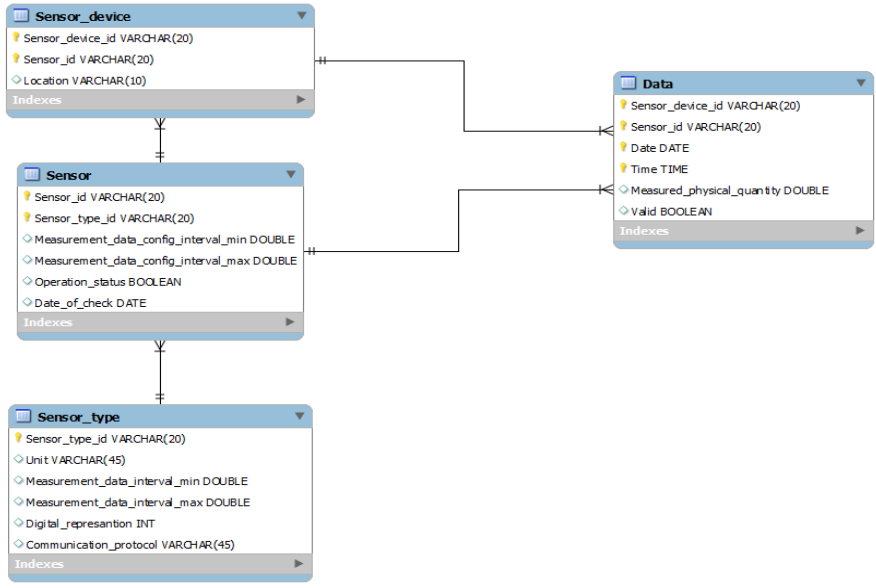

Fig. 4.: Database scheme

Data storing function implemented in the Data table is the role, that means not only storing the measured physical quantities of the instruments alone, but storing much information about the circumstances of measurement, for example date and time of insert, source of data, location of source etc. The tables named Sensor_type, Sensor and Sensor_device put through the device register function. This service provides all the advantages of a registry and gives information about the device operation. Data validation is probably the most important question in the field of building automation, because with that we can decide which data is good enough to use in building management. The data integrity or authentication is important from several approaches. First of all it is important to know if an instrument measures the right data. To check this we implemented a trigger to the Data table. Otherwise we have to be sure of the data does not change while it comes through the communication channel from the device to the database, so it is important to know whether the communication channel is safe or not. Because of the varied kind of communication channel solving this task is a very complex cryptographic role. Last but not least it is a very important factor that we do not lost data from the database, to prevent these events we use reliable Oracle computers with huge storage capacity. We implemented a desktop application in Delphi to represent the data graphically, that can export the result of the queries to Excel pivot table, and able to make charts from these data.

\section{DATA PROVIDER DEVICES}

Currently the following devices provide measurement data for the central database in the research centre:

1) Global solar exposure meter

2) Heat-pump system with air channel

3) Meteorology station

4) Heat meter

5) Building management systems

6) Internal sensor network 
The database can get data in real-time from three distinct instruments, heat pump system with air channel, global solar exposure meter and internal sensor network. Other devices like building management system, Heat meter, meteorology station saves its measured data in csv files and the database is able to process these types of data too.

\begin{tabular}{|c|c|c|c|}
\hline Type & | Communication channel & Data processing program & Sensors \\
\hline $\begin{array}{l}\text { Heat-pump system with } \\
\text { air channel }\end{array}$ & Ethemet Modbus & implemented in LabView & $\begin{array}{l}\text { temperature, pressure, } \\
\text { powwe... }\end{array}$ \\
\hline Internal sensor network & Zigbee & implemented in $\mathrm{C} \#$ & $\begin{array}{l}\text { temperature, air pressure, } \\
\text { humidity, 3D acceleration, } \\
\text { radiation }\end{array}$ \\
\hline $\begin{array}{l}\text { Global solar exposure } \\
\text { meter }\end{array}$ & Ethemet Modbus & implemented in Python & radiation \\
\hline $\begin{array}{l}\text { Building management } \\
\text { system }\end{array}$ & Csv file & implemented in Java & acces control \\
\hline Meteorology station & Csv file & implemented in Java & $\begin{array}{l}\text { wind speed, wind direction, } \\
\text { rainfall, rainfall duration, } \\
\text { rainfall intensity, air } \\
\text { pressure } \\
\text { heat quantity }\end{array}$ \\
\hline
\end{tabular}

\section{CONCLUSION AND FUTURE WORK}

As stated in this article we made a big step to meet the final aim that is construct an intelligent, sustainable building, and we can say that we established the informatics needs for this. Furthermore, we plan to migrate the MySQL database to a Microsoft SQL and an Oracle server, which enables us to develop this complex data processing system to have all the advantages of a BI OLAP technology. Also, we would like to speed up the queries from the central database, which stores a large amount of data. To realize this increasing speed in the research centre an Oracle SUN X3 server and a high-speed data connection with the supercomputer is available. Another future research goal is to provide the security of the communication channels between the devices and the database, with some cryptographic methods, mainly focusing on the Modbus protocol.

\section{Acknowledgement}

This work was partially supported by the European Union and the European Social Fund through project Supercomputer, the national virtual lab (grant no.: TAMOP-4.2.2.C-11/1/KONV2012-0010).

\section{References}

[1] G. Husi, P. T. Szemes, N. Tóth, É. Dudás: Establishment of New Research Infrastructure at Department of Electrical Engineering and Mechatronics, Faculty of Engineering, University of Debrecen. Annals of the Oradea University. Fascicle of Management and Technological Engineering, Volume XII (XXII). "IMT ORADEA" - 2013, 30.May1.June, 2013, Felix SPA, Oradea, Romania., CD ROM EDITION. ISSN 1583-0691, CNCSIS "Clasa B+" http://www.imtuoradea.ro/auo.fmte/files-2013v1/Husi\%20Geza\%202.pdf

[2] G.Husi, É. Dudás: Intelligent building infrastructure solutions for the new DEnzero project 2013.

http://www.eng.unideb.hu/userdir/vmt2/images/DEnzero/Denzero1.pdf. 